\title{
AN EMPIRICAL INVESTIGATION ON HOW BETTER HRM PRACTICES HELP EMPLOYEES REDUCE JOB RELATED STRESS AND OVERALL ECONOMIC ENVIRONMENT WRT THE SERVICE SECTOR AND MANUFACTURING SECTION
}

\author{
Inderpreet Bhogal \\ Assistant Professor \\ Intitute of Professional Education and Reserch \\ Bhopal, Madhya Pradesh \\ Bhogal.Inderpreet@Iper.Ac.In
}

\begin{abstract}
Stress - the Silent Killer, causes a great deal of Damage to the fabric of Organization. Stress can be in the form of Depression or Anxiety, which are the ultimate form of STRESS. The Research Paper Intents to Highlight Job related stress an employee experience at his workplace which can be caused due to various factors in Service as well as Manufacturing Sector and compare which Sector mostly faces the Heat of STRESS and how better HRM practices can help the Employees Cope up with the Stress caused due to Work Assignments.
\end{abstract}

The Purpose of this Research is to study the Impact of Job-related stress on Employees, how do they react to stress and how does it cause a Major Impact on Corporate Culture of an Organization and in turn major losses to Economy of the Country.

\section{INTRODUCTION}

HUMAN RESOURCE MANAGEMENT

Since the Industrial Revolution, the role of Human Resource Management has evolved from merely provide Services (Recruitment, Selection, Placement), to Strategic Business Partnership. Human Resource Management not only designs Policies but help the People at the helm of the affair to execute them Successfully. Be it a Job Analysis or Employees Career Succession, the Human Resource Management plays a Key Role in every corner of the Conception of an Organization. With the Advancement of Technology, the competition has grown to leaps and bounds and Human Resource Management plays a Vital role to give their organization the Competitive Advantage.

With dynamic Business Environment and increase in Competition, the Human Resource Manager's task becomes even more important as they must quickly analyse the Change and make their employees ready for the CHANGE, before the technology that their employees are working on becomes obsolete. Fast Paced Changes results in Work overload, More hours of work and Monotony which ultimately leads to STRESS. Gone are the days when HRM only Recruited and Trained the Employees. If the company has to gain a competitive Advantage in the Market, they just dont have to take care of the Traditional Functions of HRM such as Recruitment, Training, Performance Appraisal but also the Welfare of the Employees which includes Mental Health, Needs, Wants and Desire of their Employees, to name the Prominent Few. The Role of HCM (Human Capital Management) evolved to Human Experience Management (HXM) which will be discussed in the Next Section.

As per the Economic Times Article, Dated September 10 of the Year 2019, the estimated burden on Global Economy due to Depression and Anxiety will cost US \$ 1 Trillion in Lost Productivity Per Year. India, alone will suffer Economic Losses of Herculean 1.03 Trillion Between Year 2012 to 2030. Job Related Stress can be due to Many Factors which will be discussed in Later Sections. 


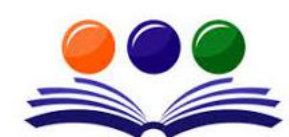

GRAND ACADEMIC PORTAL RESEARCH JOURNALS

A GLOBAL JOURNAL OF SOCIAL SCIENCES

( ISSN - 2581-5830 )

Impact Factor - SJIF - 4.998, IIFS - 4.375

Globally peer-reviewed and open access journal.

HUMAN EXPERIENCE MANAGEMENT

With Advent of Technology and the way Business Environment is changing, it is becoming very difficult for HRM to Maintain the Human Resource. The CHANGES that are brought upon the Organization and in turn on the Employees is becoming a daily routine task because of which Employees have to adapt quickly with the changing Business and Economic Environment. The Work QUICK can lead to the Mental Illness called STRESS which if not treated, ultimately leads to more serious mental Problems popularly called as DEPRESSION and ANXIETY.

Human Experience Management, a level ahead of Human Resource Management talks about Managing the Needs and Wants of the Employees. HR teams are not just hiring and firing Employees but taking care of their Welfare and Wellness. One of the Discipline called MEDICINE is one of the major contributing elements today in the Study of Organizational Behavior which talks about providing Aid to the Stressed out, Anxious or Depressed Employees. There can be many reasons because of which the Employees experience Job Related Stress but let us examine the Prominent Job STRESSORS

Ambiguity, in general sense means Unclarity. If the employees are not clear about what they need to do or what are their Job Responsibilities, they tend to become Stressed in due course of time which ultimately leads to Employee Absenteeism, Negative Attitude towards work, Hygiene related issues because of which the company looses out on the Man Hour worked.

Job Overload arises basically because of 2 reasons i) Tight Deadlines ii) Less knowledge about work. According to a recent survey, almost $50 \%$ of the employees experience tight deadlines either every day or once in a week. As the Deadline approaches, the Stress starts to increase and is at the top notch when near to the Deadline. Due to face paced changes in business environment, some the technology that employees previously worked on becomes obsolete and when the new technology is introduced, other than the routine work, the employees have to learn the new technology which overburdens them and ultimately leads to Stress related issues.

3.

LONG WORKING HOURS

KAROSHI, translates to Death by Overwork. With Dynamic and Competitive Business environment, the work element which is affected the most is the LONG WORKING HOURS. With Job Design transforming from GENERIC to more COGNITIVE, the workload on the employees have increased furthermore. COGNITION means Mental efforts an employee puts in his/her daily routine work. The General 9 Hours Working Shift is never ending. In Japan, almost 90\% of the Employees Overwork due to tight Deadlines. The reason is that their Working Age Population is Slowly declining, and Employees are retiring at faster pace. Due to this, the Working Age population are feeling the head as the Government is Forcing the Enterprises to produce more to cater to rise in Demand in Domestic as well as International Markets, if they have to maintain their Position in the list of top 10 GDP's of the world. Anyhow, the pressure of Economy is transferred to Employees.

India on the other Hand has a good working Population however, only relying on this statistic is not enough to prosper. The Literacy rate, Standard of Living are some of the reasons why India is not able to use its full potential and the Workload again is at the mercy of Few which ultimately feels the Pressure. Due to Long Working Hours, the employees feel Stressed out, reach extreme Fatigue levels, Low Energy because of which they are not able to give their $100 \%$ on their Job.

\section{LITRETURE REVIEW}

With Dynamism in Business Environment, the Organization must adapt with the Changes quickly to avoid Market Share Loose out. A lot of Studies has been conducted before to find out the Work Related Stress that employees experience and its Ill effect on Company's Revenue. The Empirical Investigation done through this Research Paper will not only highlight the Key reasons for Stress at workplace and to the Economy overall but also how the Companies can introduce certain programs to help employees cope up with the Stress.

\section{EVIDENCE FROM LITRETURE}

After Investigating certain Facts, it can be concluded that certain HRM Practices can reduce Stress from Employee and make them more ENGAGED. A Disengaged employee causes a lot of damage to the very Fabric of the organization and results in the decline of Revenue earned by Organizations. If these Practices are followed properly, the Employees will be more productive, and the Stress can be minimised from the Workplace. 


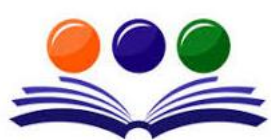

GRAND ACADEMIC PORTAL RESEARCH JOURNALS

A GLOBAL JOURNAL OF SOCIAL SCIENCES

( ISSN - 2581-5830 )

Impact Factor - SJIF - 4.998, IIFS - 4.375

Globally peer-reviewed and open access journal.

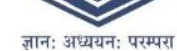

According to Gallup Poll in USA, the US companies Looses $\$ 450$ - \$550 Billion every year because of Disengaged Employees and $80 \%$ of Disengagement is caused due to Stress.

\section{RESEARCH METHODOLOGY}

This research has been conducted using primary research technique where data is directly collected from the respondents rather than depending on data collected from previously done researches. I wanted to carry out research that addresses a certain problem and which requires in-depth analysis. Paper's motive is to highlight and find out the key factors that causes stress at Workplace. This primary research has helped me to directly communicate with the target respondents and get the first hand feedback and their opinions on the problems and concerns related to the research. Since, this research emphasizes on the relationship of a Stress and Job Performance, I have selected Low to Mid level managers to be our target respondents. The respondents include Assistant Manager Sales, Sales Managers, Academician, human resource managers and other distinguished officials holding authorities in the reputed organizations. The responses and feedbacks of these respondents has successfully and immensely assisted us in arriving to conclusions that would surely New and Established Organizations/managers to help their Employees Cope up with the Stress caused at Workplace

During tough times like today (outbreak of Covid-19), I took necessary precautions while collecting the data supporting our research by drafting a well-structured questionnaire consisting of a formalized set of questions on the subjects pertaining to our research. The questions were created by using "Delphi Method" in 2 rounds. The respondents were asked to give their Objective replies to the series of questions about STRESSORS at Workplace. The questionnaire was virtually sent to all the respondents via e-mail on their official e-mail id's (and google form tool) and posted on Linkedin, and the responses were received in the same order. After collecting the desired responses, I then finally interpreted and analysed the data to arrive at the concrete and fruitful decisions that will help business concerns while helping the employees cope up with Stress and its different form which will inturn help the organization to Build a Strong Brand value and makes them the best Company to Work.

Structured interviews consist of a series of pre-determined questions that all interviewees answer in the same order. Data analysis usually tends to be more straightforward because researcher can compare, and contrast different answers given to the same questions. Other method that was used was Structured Interview Method which was performed over the Call and Google Meet Application. As I wanted to Capture the Qualitative Aspect of the Respondent, I happen to Interview 7 Employees of EPIC ONESOURCE PVT LTD, which is one of the Financial Service Provider Located in Vadodara, a City in Gujrat. The responses of all the 7 Employees were Recorded in Qualitative form.

To analyse the Study from International Perspective, the response was collected from the Employees/Expatriates working in United States of America. The Questionnaire were mailed to the participants to which they responded and helped me to have a view on the Silent Killer from International Perspective.

\section{HYPOTHESIS}

H1 - There is a significant Positive Relation between Low Performance, Disengagement of Employees and Regular Absenteeism from work due to Job Related Stress

H2 - There is a Significant Positive Relation between Introducing Welfare Programs, Frequent Feedback Practices and Recognizing Employees and Low Stress which in turn motivates the Employees to Perform as desired

\section{DATA ANALYSIS TECHNIQUES}

Data Analysis of the Responses was accomplished by using the Pie Chart Method, which was auto generated by Google Form Application which helped me to realise the relation between various factors of Stress at workplace and how the Organizations can help their employees to cope up with it. More of Qualitative analysis was done in Structured interview Method as the Questions that I asked were from the Questionnaire itself.

\section{RESEARCH FINDINGS}

The Finding hereby will be discussed Question wise according to the Analysis done and Responses Received from Individuals from Service and Manufacturing Sector

Q1) Which Sector are you Employed in 


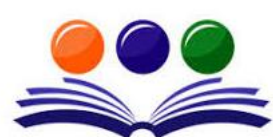

GRAND ACADEMIC PORTAL RESEARCH JOURNALS

\section{A GLOBAL JOURNAL OF SOCIAL SCIENCES}

( ISSN - 2581-5830 )

Impact Factor - SJIF - 4.998, IIFS - 4.375

Globally peer-reviewed and open access journal.

Out of 80 Respondent of Questionnaire and 7 Interview Conducted, 90\% of the respondent belong to Service

Sector whereas $10 \%$ of the Respondent belonged to Manufacturing Sector.

\section{Sector Comparison}

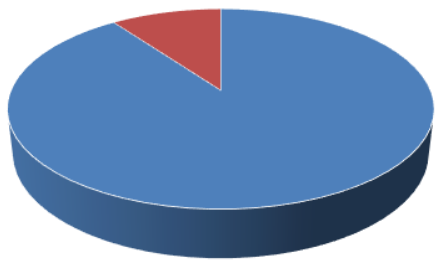

- Service - Manufacturing

Figure No. 1

Q2) What are your Normal Working Hours

Through this Questions, I wanted to capture the routine Working Hours of the Employees which their Organization demands (Overtime Not Included). Out of 80 Responded, 50\% Stated that there normal working hours are 9 Hours whereas the other 50\% Respondent stated that their shift was of $6-7$ Hours. Further analysis was done to find out which Sector (Service or Manufacturing) had longer Shift and it was found that Service Sector had longer Working Duration which average out to be 85 Hours per day (Overtime not Included).

\section{Normal Working Hours}

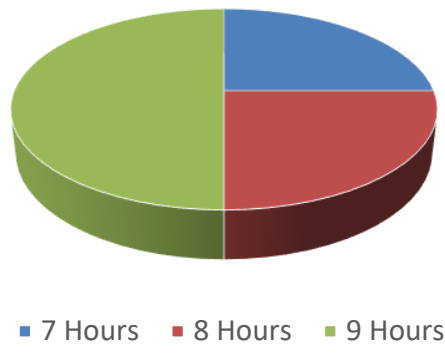

Figure No. 2

Suzy Parkinson's Article in GQR, Dated August 9, 2018, “According to The New York Times, Perpetual Guardian, a firm that manages trusts, wills and estates, eliminated an entire day's work from their typical five-day, 40-hour workweek for six weeks earlier this year. It was curious to see what this change would do for its 240 employees - and how it would affect the business.

It turns out that employees reported a 24-percentage point improvement in work-life balance. They said they spent more time with their families, exercising, cooking and working in their gardens and returned to work more energized. Staff stress levels were reduced by 7 percent. I will analyse this viewpoint later during the Findings.

Q3) How often do you Engage in Overtime?

Overtime refers to any hours worked by an employee that exceed their normally scheduled working hours. 


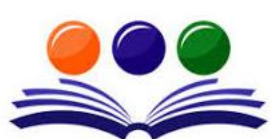

GRAND ACADEMIC PORTAL RESEARCH JOURNALS

\section{A GLOBAL JOURNAL OF SOCIAL SCIENCES}

( ISSN - 2581-5830 )

Impact Factor - SJIF - 4.998, IIFS - 4.375

Globally peer-reviewed and open access journal.

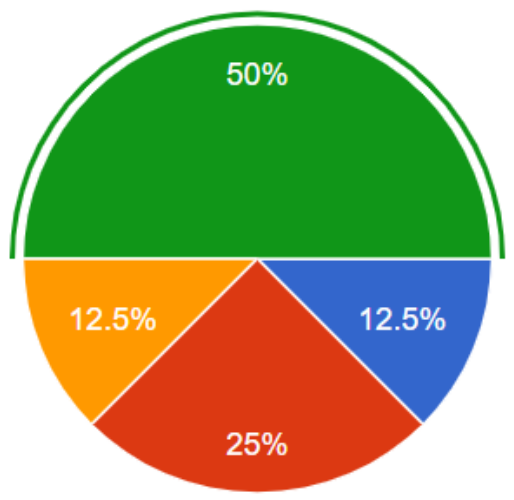

Once in a Month

Once in Fortnite

Once in a Week

Almost Everyday

Figure No. 3

It is Quite Evident from the responses that were received, that $50 \%$ of the Employees indulge in Overtime and $37.5 \%$ of the Employees engage in Overtime once every 15 days. According to First Post Article dated November $21^{\text {st }} 2019$, there are few negative Effects related to Overtime which are More Fatigue, Access Alcohol Consumption, Heart Related Diseases, Stress Dominant life to name the few Prominent Risk Factors. The most common reason why Employees Indulge in overtime is due to WORK OVERLOAD, STRIVER SYNDROME, EXTRA MONEY, without realising the fact that they are risking their Health due to Overtime. Ultimately if the employees are facing the above health problems, they wont be productive for the organization which will result in sluggish performance. With my Findings I might try to solve this problem. Almost 70\% of the Respondent are from Service Sector who experience OVERTIME issues.

Q4) How Often do you find yourself Dealing with Deadlines?

Deadlines - One of the Major Factor that causes WORK OVERLOAD has been another major problem that causes Stress amongst Employees across various Sectors. Almost 50\% of the Respondent Agreed that they indulge in Overtime once in a Week and 25\% of the Respondent Indulge in Overtime Almost Every day.

Work Overload Ultimately leads to Physical, Mental and Emotional Exhaustion which results in problems such as Headache, Irritability, and the employees detach themselves from Work which leads to Slackness in Performance
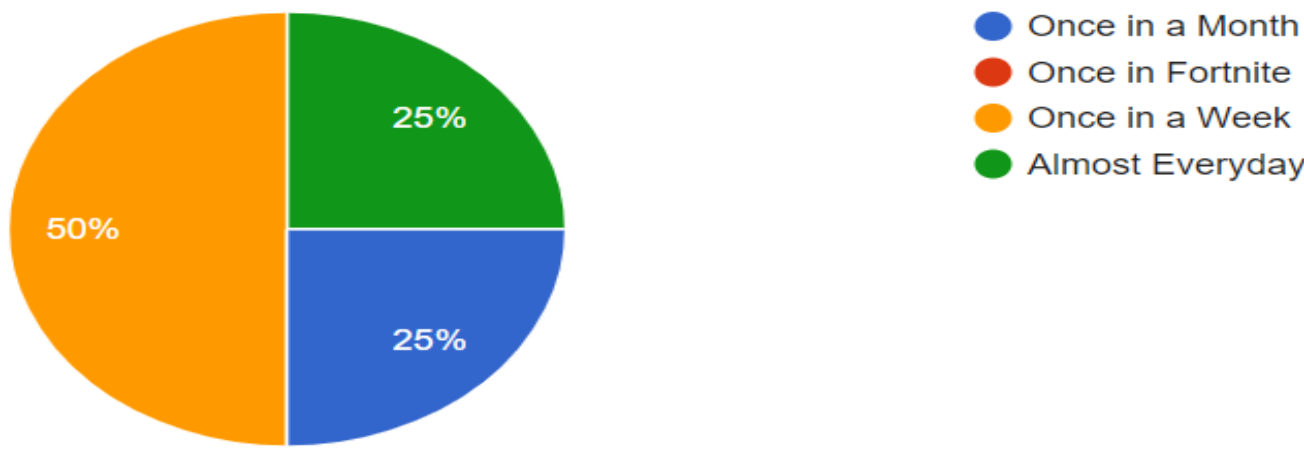

Figure No. 4

Q5) Do you Experience Job Related Insecurities?

Fear of loosing something, can be quoted as a simple meaning of the word Insecurity. And among the Employees, this is one of the major concerns, JOB INSECURITY. With Dynamism in business environment, technological advancement and competition, the skills that an employee possess can become obsolete which makes them rather ineffective for organization. Organizations can decide upon training the employees on new technology, however, from company's perspective, training can involve huge overhead costs which companies 


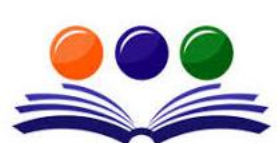

GRAND ACADEMIC PORTAL RESEARCH JOURNALS

\section{A GLOBAL JOURNAL OF SOCIAL SCIENCES}

( ISSN - 2581-5830 )

Impact Factor - SJIF - 4.998, IIFS - 4.375

Globally peer-reviewed and open access journal.

usually relinquish in case the skills are available readily in the market. This results in layoff, retrenchment and ultimately the employee has to suffer.

Out of 80 Respondents, $66.6 \%$ have stated that they experience Job related Insecurities which eventually put them under greater risk of experiencing STRESS. The employees have to be up to date with the new technology that is being introduced to make them a GOOD - FIT for the organization. Will discuss the remedies on how the Organization can help the employees overcome this problem.

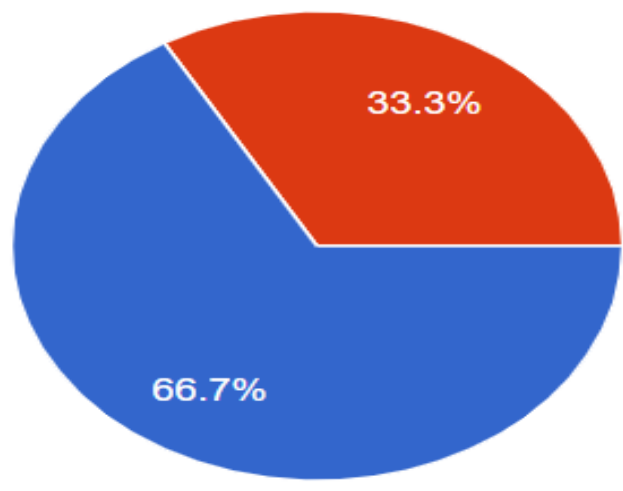

Figure No. 5

Q6) How often does your HR, Team Manager, Operations Manager meet with you to provide Job Related Feedback

According to an article in TRUQU, the Feedback can help reducing BRAIN DRAIN amongst the employees. Not many people find it easy to understand whether they do everything right on their own. As a consequence, their confidence and joy for work may drop while their minds are getting clouded with doubt and the stress level is climbing up. Thus, an expert look from the outside and merely a few words of constructive feedback can help your colleagues feel like they're on the right track and don't make any fatal mistakes.

Besides making employees feel valued and recognized, a manager who gives regular feedback shows care for what's going on in their team. Feedback is a sign of a manager's interest in their staff's activities and work results, without which some team members may think they're neglected and become disengaged. So, by frequently motivating your colleagues with constructive feedback, you might notice them turning more committed and loyal shortly after.
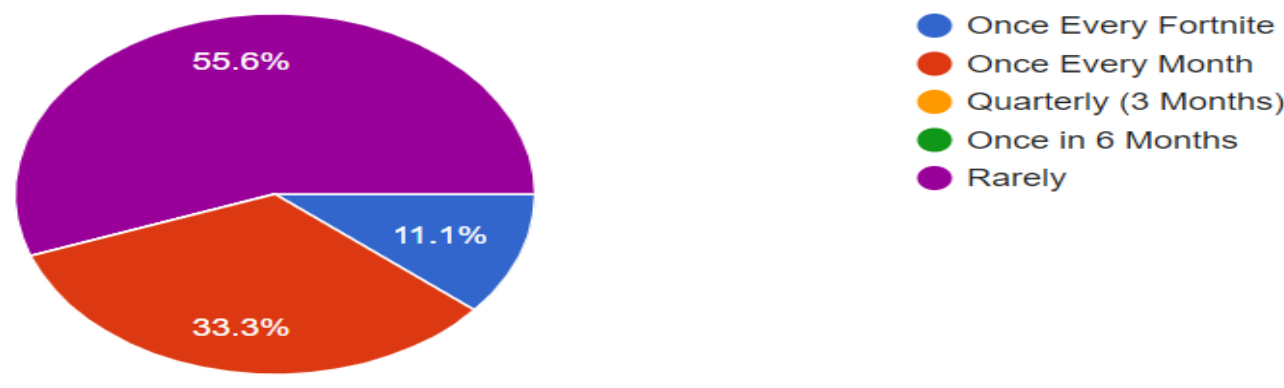

Figure No. 6

However, research shows shocking results. Almost $56 \%$ of the Respondents stated that they rarely get any feedback from their Management team which can be concerning. Especially in service sector, where the Mental Workload is more than Manufacturing Sector, the Employees constantly look for feedback to improve their performance and be more Motivated to work. If the employees are not aware about how they are performing, 


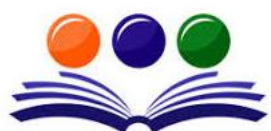

GRAND ACADEMIC PORTAL RESEARCH JOURNALS

\section{A GLOBAL JOURNAL OF SOCIAL SCIENCES}

( ISSN - 2581-5830 )

Impact Factor - SJIF - 4.998, IIFS - 4.375

Globally peer-reviewed and open access journal.

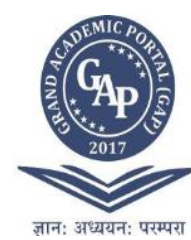

the working becomes quite ambiguous and as stated above, the employees disengage themselves from the work.

Q7) Does your Manager/Company provides you Freedom to take decision about your Work Environment? If employees have the control over the Work Environment they delve in, they feel more comfortable in performing a task. Control over work environment depends on certain factors such as Situation, Experience of Employee handling that particular task, Leadership Style(Autocratic, Democratic, Free Reign). If a fresh recruit is given freedom to take decision of his task performance it may lead to Bottle Necks as he has less experience of the matter, however, if an experience employee is given freedom, he may perform better than expected as an experience employee will feel suffocated. Through this question, I wanted to capture the degree of freedom an employee has of his Work Environment in both Service as well as Manufacturing Sector.

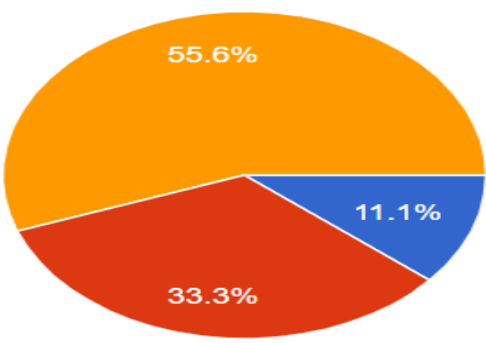

Yes
No
Depends on Situation

Figure No. 7

Only $11 \%$ of the respondent stated that they have the control over their Work environment whereas $55 \%$ of the respondent stated that it depends on the Situation. $33.3 \%$ of the respondent replied that they have no control over the Decision-making process which is quite alarming as they might feel suffocated owing to lack of Decision taking ability.

Q8) Does your Company provides Wellness Program (Yoga/Fitness Training/Gym Membership) for you? How often does your Company Organize such Programs?

Task these days involve more Cognitive work rather than physical work, all thanks to latest Technology being introduced in Job Function. With this Question, I wanted to know how well the companies are taking care of their employees Mental and Physical Wellness as it is a must these days to keep your employees Mentally, Physically and Morally Fit and engaged at work. 89\% of the respondent replied that their companies Never or rarely organize such Wellness program, which is quite alarming.

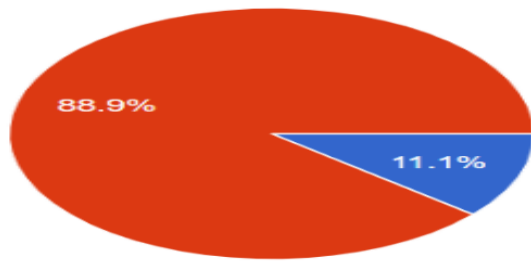

\section{Figure No. 8}

Q9) Does your Company Organize Social Gathering?

According to Jit S Chandan's finding in his book on Organizational Behaviour, one of the best cultures which an organization can adopt to help their employees to cope up with the Stress is to promote socializing amongst their employees. Socializing can be accomplished through many ways such as Award Functions, Team Dinner, Quarterly Performance Meetings and Appraisals through which they employees comes to know the people they are working with. Group Cohesiveness increases if the organization gives them a 


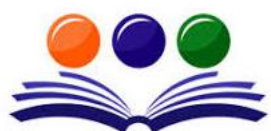

GRAND ACADEMIC PORTAL RESEARCH JOURNALS

A GLOBAL JOURNAL OF SOCIAL SCIENCES

( ISSN - 2581-5830 )

Impact Factor - SJIF - 4.998, IIFS - 4.375

Globally peer-reviewed and open access journal.

chance to Gel up with their Colleagues, Peers, Subordinates. 79\% of the respondent across Manufacturing and Service Sectors stated that there was no social gathering which was organized by their companies, neither offline nor online.
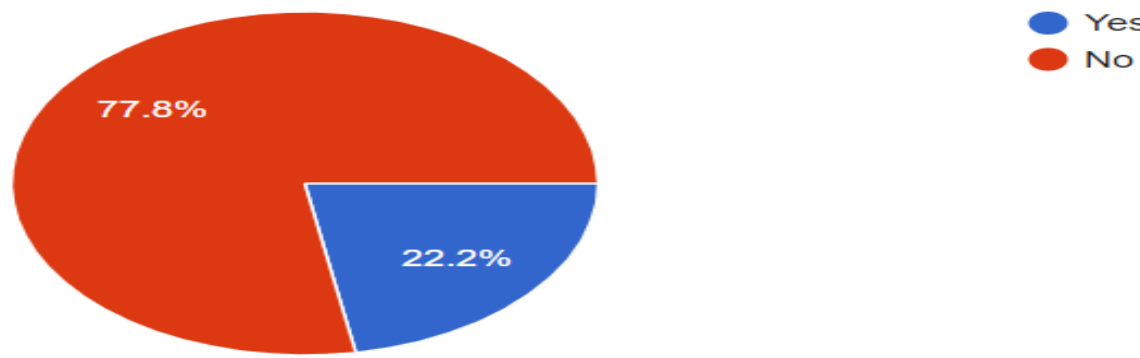

Figure No. 9

\section{WORKING ON RESOLUTION}

With this section, I tried to apprehend the responses from Respondent as to how their Organization can try to reduce the Stress levels that arises due to Work/Job Load. The Questions that were asked, originated from the Previous section. This section Highlights the key programs/practices that the Managers/HRM/C - Suite team can adopt to make the workplace more motivating and reduce the Job-Related Stress and increase EMPLOYEE ENGAGEMENT.

According to article posted by Dana Wilkie, Dated April 20, 2020, SHRM, following measures must be taken to help employees cope up with Stress issues at workplace

- Encourage your team to take advantage of stress-management webinars, wellness tips or programs, and yoga or meditation classes. Set an example by using these resources yourself.

- Make sure workers are taking regular breaks and be sure to take them yourself.

- Encourage employees to exercise daily, take time for friends or a significant other after work, pursue hobbies, listen to music, and take time off.

Q10) Do you think its better for your Company to Adopt WFH/Flexible Working Hours System

To this Question, 57\% of the Respondent stated that the company should adopt Work from home or Flexible working hours. According to article published by Adi Gaskell, Forbes, Dated January 11 2016, way before Pandemic Era, "It found that employees who were placed on a flexibility program were both happier at work and less prone to burnout and psychological stress than their colleagues who were not on the program". Of Course, working from home or flexible shifts has their own disadvantages, like Motivation, Typical Team bonding Challenges, Keeping a track of daily Task Performance, to name the few, in spite of these challenges, the Employees can easily manage their work life balance which is not possible during the tight schedules usually followed by the Organizations.

Quality Circles, which is that Branch of Human Resource Management that keeps a track of Work - Life Balance of an employee should evolve with such programs (WFH/Flexible Shifts) which can be beneficial for the Organization as well as the Employees. There are other benefits too linked with WFH/Flexible shifts such as it Improves D\&I, Increase productivity, Improves Employee Engagement. And according to the Employers, it saves them a lot of Overhead costs. While $33.3 \%$ of the Respondent were not sure, $11.1 \%$ of them felt that the HR should stick to Fixed Shift regime.
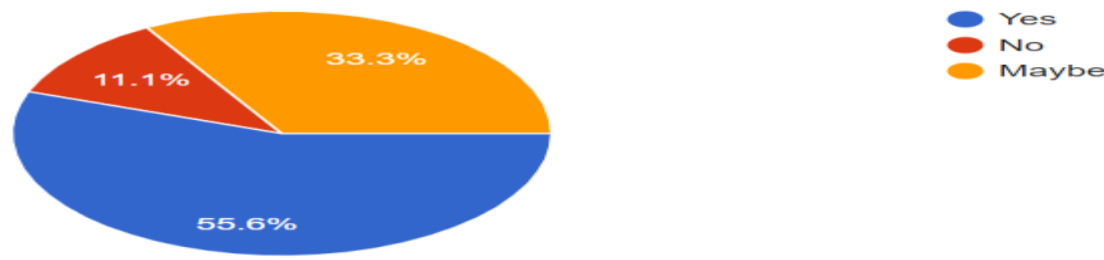

Figure No. 10 


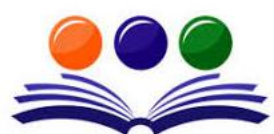

GRAND ACADEMIC PORTAL RESEARCH JOURNALS

A GLOBAL JOURNAL OF SOCIAL SCIENCES

( ISSN - 2581-5830 )

Impact Factor - SJIF - 4.998, IIFS - 4.375

Globally peer-reviewed and open access journal.

Recent UK research by Capability Jane reveals the demand for flexible working is substantial in which, $\mathbf{9 2 \%}$ of Millennials identify flexibility as a top priority when job hunting, $\mathbf{8 0 \%}$ of women and $\mathbf{5 2 \%}$ of men want flexibility in their next role, $\mathbf{7 0 \%}$ of UK employees feel that flexible working makes a job more attractive to them and $\mathbf{3 0 \%}$ would prefer flexible working to a pay rise.

Q11) Do you think it's better to Hire more Personnel (Full Time/Part Time/GIG) to avoid Work Overload/Tight Deadlines Situations?

Right People at the Right Place and the Right Time and at the Right Job, has been the Motto of Human Resource Management since Yesteryears. Onboarding process has taken a Strategic Position in an organizational Core Planning process. The question tries to Capture the true sense of Human Resource Management which predicts that the HRM should have more staff than it has presently. There are instances where a project/assignment may arise and the client demands an urgent completion of the work which ultimately leads to tight deadlines and Work Overload for Employees which results in Stress at work place. Having right number of people whether Part Time/Full Time can help shred the workload and reduce the Stress at workplace. To this Question, 44\% of the Respondent agreed that the company should onboard more staff either Full Time/Part Time/WFH and 33\% were not sure about this. The remaining 23\% stated that it is not required. When I interviewed HR Manager Divya, EPIC Ventures Pvt Ltd, she stated that the company can onboard some GIG workers to shred the workload from the regular staff so they have less burden of work and hence removing stress from the Workplace
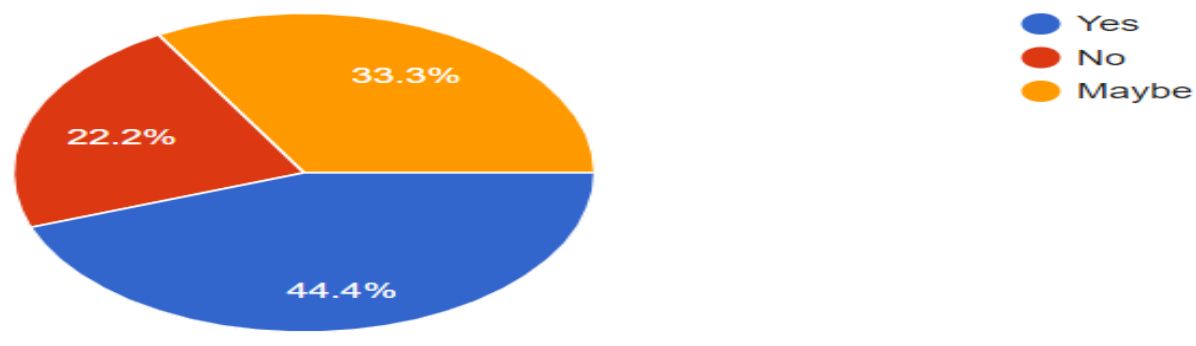

Figure No. 11

Q12) Do you think your HRM/Team Manager/Operations Manager should provide Job related Feedback more often to avoid Job Related Insecurities

The Biggest Stressor in an employee's life is Job Security. Even before Pandemic Era, the biggest factor that contributed to the Stress in an employee's life was his/her JOB SECURITY. With Paradigm shift in the way company operates, Technological advancement and Dynamism in Business Environment, the Skills that an Employee possess can become Obsolete, because of which an employee may lose his/her ground of employment and become a part of Lay Off/Retrenchment. This is the biggest fear in the Minds of Employees which may arise due to lack of position power as well.

According to an article published by SHAWGIBBS on their website "Open communication is critical in leadership - keeping employees up to date regarding changes, expectations and their own performance not only keeps them on track but also reduces feelings of stress and anxiety - after all, there is nothing worse than being kept in the dark. As a manager be sure to keep your team abreast of the latest developments and departmental changes. What's more, open communication is a two-way street and the more you communicate with your employees, the more likely they are to share concerns, ideas and thoughts making for much stronger working relationships and a healthier overall company culture."

To this Question, 89\% of 80 Respondent Agreed that their HRM should provide feedback related to their performance which clearly suggests that the practice is being overlooked due to other factors which may wreak havoc the employees Motivation levels and the Employees may feel more insecure owing to lack of communication with regards to their own Job Performance. 


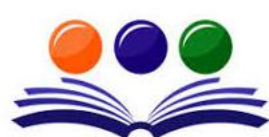

GRAND ACADEMIC PORTAL RESEARCH JOURNALS

A GLOBAL JOURNAL OF SOCIAL SCIENCES

( ISSN - 2581-5830 )

Impact Factor - SJIF - 4.998, IIFS - 4.375

Globally peer-reviewed and open access journal.

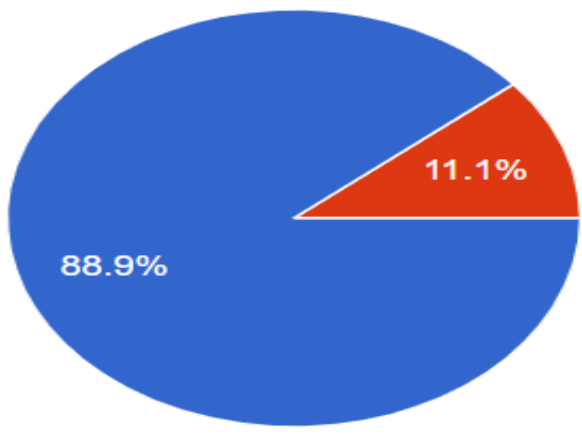

Figure No. 12

Q13) Do you think that your Company should give you more freedom to take decisions in your Work Environment?

This Question is quite debatable since Decision Making usually rests with the Managers/Leaders in a work system. There are certain factors which affects the Decision-Making Process should or should not be given in the hands of an Employee. Experience, Skills, Leadership Style can be some of the factors that influences the Decision-Making abilities of an employee. However, 33\% of the respondents feel that they should be given freedom to take decisions of their Work Environment. While 55.6\% of the Employee are not sure if it will affect their Mental health in anyway.

Q14) Do you think that your Company should organize more Wellness (Yoga/Fitness Training/Gym Membership) Program more Often?

Respondent from both the Sectors, Services and Manufacturing agreed upon the fact that the company should organise Wellness Program quite often Programs such as Yoga Workshops, Gym Membership, Fitness Training should be inculcated in the routine. It is a proven fact that Mentally and Physically fit Employees are more effective and efficient in Performance. Meditation, Yoga Asans and Cardio exercise can be easily organised for the employees on regular basis to break the monotonous and not to forget hectic work schedule and will help the employees cope with the Stressful Situations. $44.4 \%$ of the respondent agreed that their organization should include Wellness program, while $33.3 \%$ were not sure about the effectiveness of it.
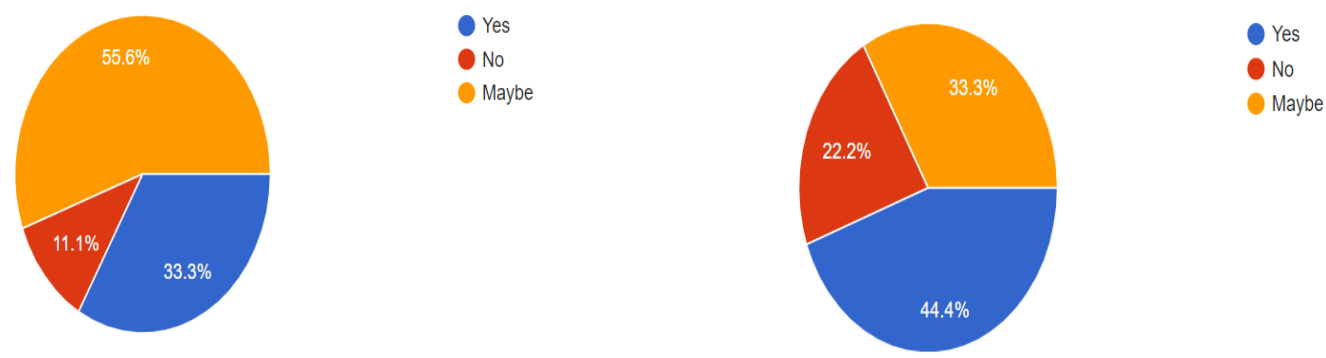

Figure No. 13

Figure No. 14

Q 15) Do you think your Company should organize more Social Gatherings (Award Functions/ Team Dinner Outing/Cultural Events)

$56 \%$ of the respondents stated and agreed that their companies should organize social gathering, in a form acceptable by the Organizations standard. Social gather can be in the form of Award Functions, Team Dinner Outing, or Cultural Events to name the few. Social Gathering helps a Team Leader/Operations Leader in many ways such as improving Group Cohesiveness, Nourishing Group Dynamics like Team Building to name the few Positives. According to an article published by TALENT INTELLIGENT, Dated June 11, 2018 (Pre - Pandemic 


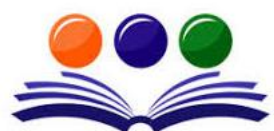

GRAND ACADEMIC PORTAL RESEARCH JOURNALS

A GLOBAL JOURNAL OF SOCIAL SCIENCES

( ISSN - 2581-5830 )

Impact Factor - SJIF - 4.998, IIFS - 4.375

Globally peer-reviewed and open access journal.

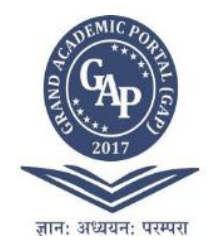

Era), “A multi-year research effort from The Gallup Organization suggests having friendships in the workplace can have a significant impact on employee experience. The research found personnel who had a best friend at work were 43 percent more likely to report having received praise or recognition for their performance in the last seven days."

Those employees also reported significantly higher levels of healthy stress management, even though they had generally experienced the same levels of stress as ones who didn't have a best friend at work." While 33\% of the Respondent were against the idea of organizing social gathering because of Pandemic Era, Introvert Nature, family commitments.
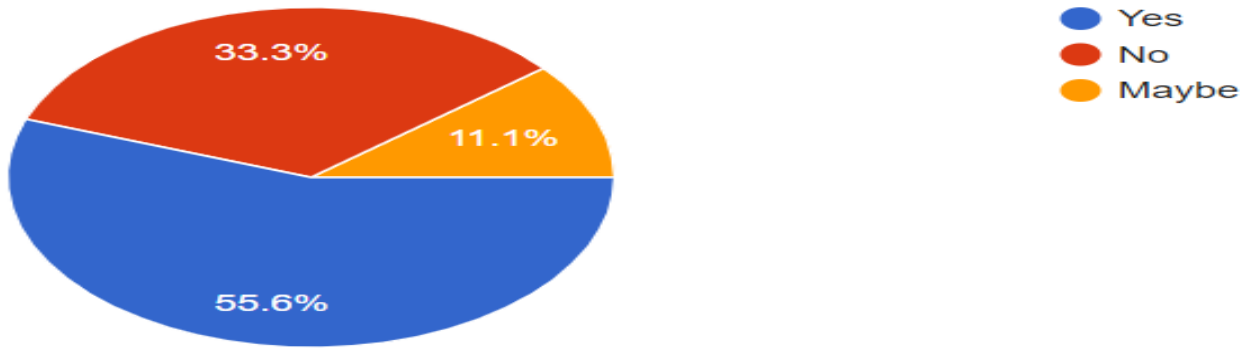

Figure No. 15

\section{STRUCTURED INTERVIEWS FINDINGS}

Through Structured Interviews with 5 Respondent, I tried to have a deeper Insight on the Objective of this Research Paper. Out of 5 Interviewees, 3 are from India and 2 are from United States of America, 4 from Service Sector and 1 from Manufacturing sector. The Questions asked were same which were present in Questionnaire. Mr. Prashant Shegde (HR Head, Epic Ventures Pvt. Ltd.)

Ms. Divya Sharma (HR Executive, Epic Ventures Pvt. Ltd.)

Mr. Rajesh Sonawane (Head - Accounting, Epic Ventures Pvt. Ltd.)

Mr. Premjit Sethi (Project Lead, Vistex Software Pvt Ltd, Chicago Illinois, US)

Ms. Anjali Ojha (Sr. Software Engineer, Infosys, Onsite Placed, New York, US)

All the Interviewees had almost similar Response to the questions asked. Interviewee working overseas stated that their Human Resource Management has started conducting more online meetings through dedicated video conferencing software to provide them regular feedback and also organizes various e - cultural events and reward and recognition programs to keep high motivation levels. They also stated that the Human Resource Managers have adopted e - Fitness regime in which, every Friday (Mr. Premjit Sethi, Vistex Software Pvt Ltd) and every Saturday (Ms. Anjali Ojha, Infosys, New York, US), the employees undergo Zumba fitness workout and Cardio exercises. They stated that it has helped improved their Mental Health and they can concentrate more on their work.

The Interviewee from India stated that the social gathering happens rarely now due to Pandemic, however, the Human Resource Management Team from EPIC ventures provide feedback every 2 weeks to their employees about their performance which has kept their employees engaged. All the respondents stated that their organization should hire more Individuals to shred off the load from the employees and keep the deadlines in tact and meet the daily and monthly targets. They also feel that the Human Resource Department should organize e - social activities to keep the zeal of a team spirit alive even in the Pandemic era.

\section{RESEARCH CONCLUSION}

Either it's a Service Sector or Manufacturing sector, the Cognitive Task has taken over the Generic Physical Task Structure which involves more or thinking abilities rather than physical abilities, all thanks to Technological advancement in the field of Artificial Intelligent and Machine Learning. Introducing technology was supposed to make the life of the Employees and Employers easier but it only added up to the problem. Karoshi, is a Japanese word for "Death due to Overwork". Almost 95\% of the employees in Japan suffer from Overtime of 80 Hours a Month which is an alarming situation has the Mental Health is at stake. $44 \%$ of the respondent stated that they experience Overtime issues almost everyday and even if we take 1 hour of overtime, the results comes out to be approximately 30 - 40 hours of overtime every month. 89\% of the respondent (Questionnaire 


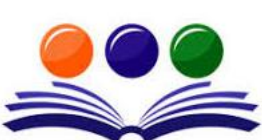

GRAND ACADEMIC PORTAL RESEARCH JOURNALS

\section{A GLOBAL JOURNAL OF SOCIAL SCIENCES}

( ISSN - 2581-5830 )

Impact Factor - SJIF - 4.998, IIFS - 4.375

Globally peer-reviewed and open access journal.

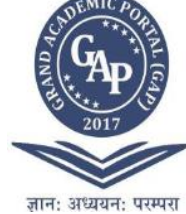

\& Structured Interviews) stated that they experience Job Related Insecurities which is another Major factor that contributes to Job Related Stress. A stressed employee generally shows signs through Absenteeism, Excessive complaining, and negative attitude towards work. Here are some tips and advise to Human Resource Managers/Team on how they can effectively handle Stressed employees at workplace.

- Prepare an effective feedback program for the employees after every 2 week, doesn't matter the channel used to communicate, either Video Conferencing or face to Face meeting to keep the employees motivated

- Organize Well Program every week/Month to keep the Mental Health of the employees intact. Happy Employees are more effective and may perform better than stressed employees

- Human Resource Management should chalk out a plan to introduce Flexible Working hours, Work from home culture. This should happen even after Pandemic Era ends as it will help them employees balance their Work - Life Regime and keep them more engaged

- Human Resource Management should organize e - social gatherings in the form or Reward and Recognition Programs, Cultural Events so as to keep the Employees Happy and which inturn will improve the group cohesiveness 